\title{
O ENCONTRO DO FRANCÊS: \\ DA IDEIA AO DOSSIÊ (2009 A 2018)
}

Em 2009, no intuito de abrir um espaço de reflexão e de formação para nossos alunos e colegas entre as três subáreas de nosso Programa de Pós-Graduação (Estudos Linguísticos, Literários e Tradutológicos em Francês) e da Graduação, nossa coordenação propôs que realizássemos um pequeno encontro anual organizado por alunos e professores. A ideia era difundir de um ponto de vista epistemológico, tanto para nós mesmos quanto para outros colegas e alunos interessados, os estudos relacionados ao francês (iniciais, em andamento ou já finalizados), com a possibilidade de inaugurar novas interlocuções.

Desde 2009, as coordenações do programa foram as seguintes: 


\section{Maio de 2009 a abril de 2011}

Claudia Amigo Pino (Coordenadora), Cristina Casadei Pietraroia (Vice-Coordenadora)

Maio de 2011 a abril de 2013

Verónica Galindez-Jorge (Coordenadora), Claudia Amigo Pino (Vice-Coordenadora)

Maio de 2013 a abril de 2015

Véronique Braun Dahlet (Coordenadora), Verónica Galindez Jorge (ViceCoordenadora)

Maio de 2015 a abril de 2017

Adriana Zavaglia (Coordenadora), Eliane Gouvêa Lousada (Vice-Coordenadora)

\section{Maio de 2017 a abril de 2019}

Eliane Gouvêa Lousada (Coordenadora), Adriana Zavaglia (Vice-Coordenadora)

Chamado mais tarde de Encontro de Pesquisas do Francês, o evento acontecia inicialmente num só dia e consistia em mesas-redondas temáticas, compostas de trabalhos apresentados por alunos de iniciação científica, mestrado e doutorado e moderadas por docentes do programa, nas mais variadas temáticas: a tradição e o contemporâneo, estudos comparativos e contrastivos, relações entre o Brasil e o estrangeiro, estudos metropolitanos e canônicos, estudos da crítica e da criação em termos de literatura, língua, ensino e tradução.

Atualmente, as pesquisas de nossos professores, às quais se ligam as dos alunos do PPG, são as seguintes:

Na linha Estudos linguísticos e didáticos, há projetos que se debruçam sobre o tema do ensino e aprendizagem de língua francesa para contextos gerais e específicos (profissionais e universitários), das tecnologias da comunicação e da informação, do trabalho educacional, dos gêneros textuais e letramento e do contato e identidades das línguas e culturas. Em relação à literatura, os projetos dos colegas podem ser divididos em: questões contemporâneas, criação e crítica e literaturas em relação. No domínio dos estudos da tradução, sobressaem as análises críticas, lexicológicas ou poéticas, colocando ou não em relevo o aspecto cultural.

Tais pesquisas se desenvolvem há muito tempo. Em nosso Encontro de Pesquisas de 2010, no entanto, além da publicação de um Caderno de Resumos, já constante da edição anterior, foram também publicados os Anais do Evento com os resumos expandidos. Também resolvemos nesse ano fazer um lançamento de revistas e livros relacionados à área e um coquetel. Nos anos seguintes, o formato se manteve, com algumas inovações. Em 2012, o evento passou a ser de dois dias e a ter um logotipo, criado graciosamente por Rodrigo Puelles, a quem muito agradecemos: 


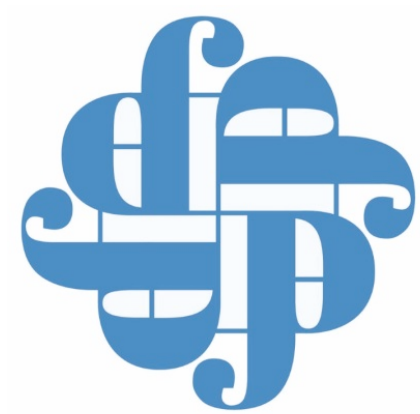

Em 2013, inserimos na programação a conferência de um aluno de doutorado que havia sido agraciado com o Prêmio USP de teses daquele ano. Em 2014, não houve conferências, mas sim ateliês, de alunos e de convidado estrangeiro. Em 2015, voltamos com as conferências, mas desta vez realizadas por convidados internacionais, na abertura dos dois dias do evento. Nesse ano, envolvemos ainda mais nossos alunos doutores, que passaram a coordenar as mesas mediadas por docentes. Em 2016, uma das conferências passou a ser a de encerramento, formato esse que se mantém até atualmente. Alunos de outras instituições passaram a se interessar pelo evento. Em 2017, passamos também a chamar colegas de outras faculdades na qualidade de mediadores, expandindo, assim, o alcance do evento e diminuindo a sua endogenia inicial.

É importante ressaltar que nenhum desses encontros teria sido possível sem o incansável auxílio de nossos monitores, alunos de todos os nossos níveis de formação, fossem eles estagiários com bolsa anual que nos apoiavam em vários aspectos acadêmicos e administrativos da graduação e da pós-graduação ou voluntários que estavam sempre prontos para o que desse e viesse! Aqui expressamos os nossos mais sinceros agradecimentos a esses nossos queridos alunos!

Na coordenação de maio de 2015 a abril de 2017, resolvemos solicitar aos participantes dos eventos com apresentação de trabalho que enviassem seus artigos para fazermos uma publicação. Expandindo sua vocação formativa, além de propiciar a nossos alunos e demais interessados a oportunidade de desenvolver sua capacidade argumentativa nos debates, nosso Encontro de Pesquisas passou também a contribuir com o aprimoramento de suas capacidades acadêmicas na expressão de diferentes gêneros textuais (resumo, apresentação oral e artigo). Vários alunos enviaram seus textos cuja avaliação obedeceu aos critérios da revista Non Plus. Aqueles aprovados para publicação (derivados das comunicações dos encontros de 2015 e 2016), dando origem a este dossiê, representam aqui a variedade de assuntos desenvolvidos pelos trabalhos que têm alguma relação com o francês, seja no ensino, na língua, na literatura ou na tradução. Além desses artigos, dispostos em ordem alfabética pelos primeiros nomes dos autores, contamos também com o texto referente à participação de um dos conferencistas de abertura de 2015 .

No texto que abre este dossiê, intitulado "Pour la traduction" (Pela tradução), Michel Riaudel, autor e conferencista do evento, trata da alteridade e da apropria- 
ção envolvidas na tradução, que relaciona mundos conflitantes para a necessária confrontação de diferentes epistemologias. Para tanto, convoca Eduardo Viveiros de Castro e seu conceito de "transdução", emprestado a Gilbert Simondon, e Antoine Berman em sua reflexão sobre o vínculo entre trabalho crítico de interpretação e tradução. Para traduzir o outro, falaremos, como questiona-se Riaudel, na língua do outro, na nossa língua ou numa outra, que ele chama de "língua franca"? Ao terminar seu texto com uma interrogação, o pesquisador nos convida a refletir, na instabilidade de nosso equilíbrio, reflexo da noção simondoniana e castriana, sobre o contínuo cultural e as assimetrias das descontinuidades geográficas para além de quaisquer fronteiras num espaço de translação.

Na esfera dos estudos linguísticos e didáticos, a mestranda à época e atual doutoranda Aline Sumya apresenta, em seu artigo, uma contribuição para o ensinoaprendizagem de francês como língua estrangeira em relação às capacidades de linguagem de adolescentes aprendizes pelo gênero multimodal tutorial em vídeo. Sua pesquisa tem como base o Interacionismo Sociodiscursivo (Bronckart, 1999, 2006, 2008), os Gêneros Textuais (Schneuwly; Dolz, 2004, 2010), a Semiótica Sociointeracional (Leal, 2010) e a Gramática do Design Visual (Kress; Van Leeuwen, 2006). Articulando aspectos verbais e não verbais na construção do tutorial em vídeo, a autora mostra, pela análise inicial de sua pesquisa das produções iniciais e finais dos alunos a partir de uma sequência didática por ela elaborada, que sua abordagem resultou em um significativo desenvolvimento das capacidades de linguagem dos alunos (de ação, discursivas e linguístico-discursivas).

Passando para os estudos literários, mais especificamente aqueles que se localizam nas relações entre o Brasil e a França, a doutora egressa Cleonice Ferreira de Sousa propõe compreender intertextualmente, com base em Julia Kristeva, de que modo é incorporada a presença francesa na obra de Castro Alves. O procedimento escolhido é analisar textualmente, pelas epígrafes, citações e alusões em "Murmúrios da Tarde" (poesia) e em "Polêmica" (prosa), o aspecto criativo de Castro Alves no "mosaico de citações", como diria Kristeva, de sua obra.

Já Marion Celli, na perspectiva dos Estudos da Tradução, emite em seu texto suas primeiras impressões sobre sua pesquisa de doutorado. Com o intuito de perscrutar o conceito de "linguagem" em textos escritos sobre tradução, de especialistas ou de tradutores, seu artigo coloca em destaque a obra Les problèmes théoriques de la traduction, de Georges Mounin (1963), para tentar compreender como o autor lida conceitualmente com o termo. A noção de "linguagem", segundo sua hipótese, é relevante para os Estudos da Tradução, uma vez que a atividade de linguagem é o alicerce do ato de traduzir (CULIOLI, 1990).

Entrecruzando tradução, literatura e crítica, a doutoranda Raquel Peixoto do Amaral Camargo lida, do ponto de vista dos imagotipos, com as imagens do Brasil no romance escrito pelo francês Jean-Marie Blàs de Roblès, Là où les tigres sont chez eux, e em sua tradução brasileira, Lá onde os tigres se sentem em casa, de Maria de Fátima Oliva do Coutto e Mauro Pinheiro. Seu objetivo é traçar uma re- 
lação entre essas imagens para observar suas refrações na tradução brasileira. Nas análises, a autora destaca a alteridade intercultural pelas diferenças das imagens identificadas e sua extensão em termos de campo semântico.

Voltando a uma perspectiva mais literária, a mestra Regina Cibelle Oliveira compara dois romances oitocentistas: Splendeurs et misères des courtisanes, de Honoré de Balzac, e Lucíola, de José de Alencar. Tematicamente próximos, pelo fato de tratarem da paixão, do sofrimento e da morte de cortesãs, o artigo traz à baila o exame das diferenças do tratamento dado à profissão de cortesã por ambos os autores que motivou a pesquisa e que é, aqui, relatada.

Relacionando a tradução e a língua, a doutoranda Renata Tonini Bastianello, engenheira em energias renováveis e ambiente pela Universidade Federal do Pampa e graduada em Letras-Francês pela USP, traz um estudo inicial sobre a terminologia da energia fotovoltaica com a finalidade de elaborar um dicionário bilíngue português-francês para tradutores. A necessidade de fontes de energia alternativas, como a solar, fez crescer a produção de painéis fotovoltaicos e, consequentemente, a demanda por traduções de documentos afins. Com base na Teoria Comunicativa da Terminologia (CABRÉ, 1999), nas ferramentas da Linguística de Corpus e nos ganchos terminológicos (DUBUC, 1985), o artigo mostra as contribuições da pesquisa para as áreas envolvidas.

No âmbito dos estudos literários, a mestra Thais Chauvel encerra nosso dossiê nos entremeios da temática erótico-amorosa das nouvelles de Marguerite Yourcenar "Le sourire de Marko", "Le dernier amour du prince Genghi" e "La veuve Aphrodissia". Mergulhando nesses textos, a autora do artigo faz emergir eros como seu tema principal, ou seja, de que modo sua representação (lírica de Safo) estabelece um diálogo com a paixão e o amor nos textos de Yourcenar. Nesse sentido, a poesia épica e lírica grega é apropriada nesses textos do século XX por uma representação clássica do amor, em que a dor, a velhice e a morte são destacadas.

O conjunto que perfaz este dossiê é uma pequena amostra da multiplicidade e da variedade de temas de pesquisa relacionados ao francês de nosso Programa de Pós-Graduação. Que continuem fortes, sólidos e vários! Que se multipliquem e se entrelacem!

Boa leitura!

Adriana Zavaglia e Eliane Lousada 